\title{
Environmental enrichment decreases chronic psychosocial stress-impaired extinction and reinstatement of ethanol conditioned place preference in C57BL/6 male mice
}

\author{
Amine Bahi ${ }^{1,2} \cdot$ Jean-Luc Dreyer ${ }^{3}$
}

\begin{abstract}
Rationale During the last few decades, alcohol use disorders (AUD) have reached an epidemic prevalence, yet social influences on alcoholism have not been fully addressed. Several factors can modulate alcohol intake. On one hand, stress can reinforce ethanol-induced behaviors and be an important component in AUD and alcoholism. On the other hand, environmental enrich-ment (EE) has a neuroprotective role and prevents the development of excessive ethanol intake in rodents. However, studies showing the role of EE in chronic psychosocial stress-impaired ethanol-conditioned rewards are nonexistent.

Aim The purpose of the current study is to explore the potential protective role of EE on extinction and reinstatement of ethanolconditioned place preference (EtOH-CPP) following chronic psychosocial stress.

Methods In the first experiment and after the EtOH-CPP test, the mice were subjected to 15 days of chronic stress, then housed in a standard (SE) or enriched environment (EE) while EtOH-CPP extinction was achieved by repeated exposure to the CPP chambers without ethanol injection. In the second experiment and after the EtOH-CPP test, extinction was achieved as described above. Mice were then exposed to chronic stress for 2 weeks before being housed in a SE or EE. EtOH-CPP reinstatement was induced by a single exposure to the conditioning chambers.

Results As expected, stress exposure increased anxiety-like behavior and reduced weight gain. More importantly, we found that EE significantly shortened chronic stress-delayed extinction and decreased the reinstatement of EtOH-CPP.

Conclusion These results support the hypothesis that EE reduces the impact of alcohol-associated environmental stimuli, and hence it may be a general intervention for reducing cue-elicited craving and relapse in humans.
\end{abstract}

Keywords Anxiety Chronic psychosocial stress - Conditioned place preference $\cdot$ EPM $\cdot$ Environment enrichment $\cdot$ Ethanol . Extinction $\cdot$ Open field $\cdot$ Reinstatement $\cdot$ Relapse

\section{Abbreviations \\ CPP Conditioned place preference \\ CSC Chronic subordinate colony \\ EE Enriched environment \\ EPM Elevated plus maze \\ EtOH Ethanol}

Amine Bahi

a.bahi@ajman.ac.ae; amine.bahi@gmail.com

College of Medicine, Ajman University, Ajman, UAE

2 Department of Anatomy, College of Medicine and Health Sciences, United Arab Emirates University, Al Ain, UAE

3 Division of Biochemistry, Department of Medicine, University of Fribourg, 1700 Fribourg, Switzerland $\begin{array}{ll}\text { OF } & \text { Open field } \\ \text { SE } & \text { Standard environment } \\ \text { SHC } & \text { Single housed colony }\end{array}$

\section{Introduction}

Research has indicated that up to $8 \%$ of the general US population meet the criteria for an alcohol use disorders (AUD) (Grant et al. 2004). Because relapse is often the main characteristic of alcohol dependence, relapse prevention is critical for long-term treatment strategies. In fact, outcome studies establish the adverse effects of comorbid anxiety disorders in alcoholism and highlight the complication of the problem. For example, both AUD and generalized anxiety disorders (GAD) are highly prevalent in the general population (Hasin 
et al. 2007). In addition, the association between these two disorders has been well documented in previous studies (Conway et al. 2006; Grant et al. 2004). Because alcoholism is highly comorbid with stress-induced social anxiety, and because adolescence represents a period of significant plasticity in the mesocorticolimbic dopaminergic system, stress exposure during this period may have unique long-term effects on reward responsivity. For instance, when discrete-time survival analysis (DTSA) was used to examine whether real-time social stress responding and social anxiety symptoms predicted 12-month alcohol onset in an alcohol-naïve sample of young female adolescents, authors reported that girls with higher levels of social anxiety, compared with baseline, had earlier alcohol initiation (Cloutier et al. 2019), suggesting that, at least in adolescent girls, increased sensitivity to social stress might be correlated with earlier alcohol drinking.

There is strong evidence, from several preclinical studies, that social stress is a strong trigger for relapse and an important factor contributing to increased motivation for alcohol consumption in rodents' laboratory animals. For example, when oral operant conditioning paradigm was used to assess the effects of repeated social defeat during adolescence on the reinforcing and motivational actions of $\mathrm{EtOH}$ in adult male open field (OF)1 mice, Rodriguez-Arias and colleagues reported that, while anxiety-like behavior in the elevated plus maze (EPM) test was not altered, social defeat in adolescence significantly increased $\mathrm{EtOH}$ consumption and motivation to drink (Rodriguez-Arias et al. 2016). Similarly, when outbred Carworth Farms Webster (CFW) male mice were socially defeated for 10 days, results have shown that EtOH consumption and preference following moderate stress were higher (13.3 $\mathrm{g} \mathrm{kg}^{-1}$ day $^{-1}$ intake) than both the mild stress group $\left(8.0 \mathrm{~g} \mathrm{~kg}^{-1}\right.$ day $^{-1}$ ) and controls $\left(7.4 \mathrm{~g} \mathrm{~kg}^{-1}\right.$ day $^{-1}$ ) (Norman et al. 2015), with the moderately stressed mice displaying escalated $\mathrm{EtOH}$ intake and self-administration during a schedule of intermittent access to alcohol (Norman et al. 2015). The same research group also reported an increase in voluntary EtOH consumption triggered by a history of social defeat stress and intermittent access to $\mathrm{EtOH}$ in male $\mathrm{C} 57 \mathrm{BL} / 6 \mathrm{~J}$ mice compared with nonstressed mice (Hwa et al. 2016; Newman et al. 2018). Similarly, stressed adult male C57BL/6 mice increased their consumption of sweet solution after ten sessions of social defeat and exhibited reduced activity in the open arms of the EPM test that was associated to a significantly persistent increase of EtOH intake compared with controls (Albrechet-Souza et al. 2017). Male and female C57BL/6J mice exposed to adolescent chronic variable social stress (CVSS) showed significantly increased adult anxiety-like behavior and drank significantly more EtOH than controls (Caruso et al. 2018). Taken together, these findings indicate that, at least in different strains of mice, prior exposure to social stress is an important risk factor for later excessive alcohol intake and affective disorders' alterations such as anxiety. Although it is obviously recognized that there is a strong association between stress-induced anxiety and excessive alcohol intake, the etiological nature of this relationship is still not fully understood and available pharmacological treatments for alcoholism have only modest long-term efficacy (Heilig et al. 2011). This prompts the question of whether pharmacotherapy can be used to tackle alcoholism. Therefore, environmental enrichment (EE) has been proposed as an alternative protective behavioral treatment for alcohol rehabilitation (for review, see Pang et al. 2019).

In studies involving laboratory animals, the nature of enrichment differs, but classically involves access to larger, more motivating/stimulating settings in cages larger and more "attractive" than those regularly used in the standard conditions, with a variety of sensory, cognitive, and motor stimuli to increase opportunities for voluntary physical activity (Nithianantharajah and Hannan 2006; van Praag et al. 2000). Results have shown that exposure to EE results in significant effects on brain morphology and physiology, enhancing neural plasticity in multiple brain regions (for review, see Sale 2018; van Praag et al. 2000) and exerting positive effects in animal models of brain injury and neurodegenerative disorders (Nithianantharajah and Hannan 2006). In addition, EE have been shown to decrease reactivity to stress as it restored hippocampal cell proliferation and ameliorated cognitive deficits in chronically stressed rats (Veena et al. 2009), with enhanced synaptic plasticity and learning, as well as memory (Arai and Feig 2011; van Praag et al. 2000). Finally, there is compiling evidence that EE has the capacity to positively affect drug-seeking behavior. In fact, the rewarding effects of cocaine were inhibited in mice reared from weaning to adulthood in EE compared with mice reared in standard environments (SE), with the mice in EE showing less activation in response to repeated cocaine administration and reduced responses to cocaine challenges (Solinas et al. 2009). The same group also reported that EE (30 days) prevented the development of cocaine-induced behavioral sensitization, CPP acquisition, as well as cocaine-induced CPP reinstatement (Solinas et al. 2008). Also, heroin-induced CPP but not behavioral sensitization was reduced in EE mice compared with SE mice (El Rawas et al. 2009). However, and contrary with what was reported with other drugs such as cocaine and heroin, EE was unable to reduce the rewarding effects of methamphetamine (Thiriet et al. 2011).

In a previous study from our laboratory, we reported that mice exposed to chronic psychosocial stress showed delayed ethanol-conditioned place preference (EtOH-CPP) extinction and increased alcohol-induced reinstatement of the EtOHCPP behavior (Bahi and Dreyer 2014). We have also reported that EE reduced anxiety-like behavior that was associated with decreased voluntary EtOH consumption, as well as reduced of EtOH-CPP acquisition (Bahi 2017b). Others have shown that priming-induced reinstatement of EtOH-CPP was blocked by 
EE (Li et al. 2015). To the best of our knowledge, no previous study has examined the efficiency of EE at accelerating stressdelayed extinction and reinstatement of CPP for $\mathrm{EtOH}$, so no direct comparison of the effectiveness of standard versus enriched environmental conditions on extinction and reinstatement of CPP has been attempted. We hypothesized that EE might attenuate/blunt chronic psychosocial stress-delayed EtOH-CPP extinction (1st experiment) and that EE would protect from stress-induced EtOH-CPP reinstatement (2nd experiment).

\section{Materials and methods}

\section{Animals}

Male C57BL/6 mice (6-7 weeks old) weighing approximately $22 \mathrm{~g}$ (experimental mice) or adults (resident mice) weighing 35-40 g were housed in standard Plexiglas observation cages. All mice were of identical genetic background and backcrossed to the parental inbreed mice each ten generations. All mice were bred locally and were kept under standard laboratory conditions $(12 / 12 \mathrm{~h}$ light-dark cycle, lights off at 6 p.m., $\sim 22{ }^{\circ} \mathrm{C}$ ). The EtOH-CPP procedure and the anxietylike behavior tests were performed during the light phase. A large number of published reports used the same lighting conditions with the housing room kept under a regular light/dark schedule (Lopatina et al. 2014; Vahid-Ansari et al. 2017). Bedding was autoclaved before use, and mice had free access to tap water and standard mouse chow diet obtained from the National Feed and Flour Production and Marketing Company LLC (Abu Dhabi, UAE). The chronic psychosocial stress procedure was approved by the local Animal Research and Ethics Committee (Protocol No. A01-12).

\section{Drugs}

EtOH $(20 \%, v / v)$ was diluted in physiological saline and injected intraperitoneally (i.p.) during conditioning and reinstatement $\left(2 \mathrm{~g} \mathrm{~kg}^{-1}\right)$. EtOH doses were selected based on our previous studies (Bahi 2012, 2015; Bahi and Dreyer 2014).

\section{EtOH-conditioned place preference}

The general procedure of the EtOH-CPP test was conducted as described in our previous studies with minor modifications (Al Ameri et al. 2014; Al Maamari et al. 2014; Al Mansouri et al. 2014; Bahi 2017b; Bahi and Dreyer 2012b). In brief, eight identical wooden two-chambered CPP apparatus $(30 \times$ $30 \times 30 \mathrm{~cm}^{3}$ ) with distinct visual and tactile cues and separated by a removable guillotine door were used. Each CPP test consisted of preconditioning (pre-CPP, day 1), conditioning (days 2-6), and postconditioning (post-CPP, day 7). Lighting within the behavioral chambers was provided by overhead lights in each of the testing compartments each measuring approximately 15 Lux at the testing floor.

During preconditioning (pre-CPP), the initial place preference was determined after each mouse was placed in the middle of the CPP box (facing the frame of the guillotine door) with 15-min free access to both compartments and the time spent in each compartment was scored. This session determined baseline preferences (whether the mouse spent significantly less/more time in one compartment than in the other, regarded as equipment bias). Mice that spent less than $35 \%$ and more than $65 \%$ of the time in either one of the compartments during preconditioning were excluded from the study. This allowed us to use an unbiased design in which both compartments were equally preferred before the conditioning session and to randomly assign the compartment paired with EtOH.

The conditioning ( $30 \mathrm{~min}^{\mathrm{m}}$ session ${ }^{-1}$ ) was performed using an unbiased procedure with the guillotine door being closed. All mice received EtOH $\left(2 \mathrm{~g} \mathrm{~kg}^{-1}\right.$, i.p.) and saline (same volume) injections every session, and the injections were altered between morning and afternoon sessions in a balanced design. The first injections were performed in the morning, and the mice were confined to one conditioning compartment for $30 \mathrm{~min}$ after the injection and then returned to their home cages. The second injections were performed in the afternoon, and the mice were confined to the other compartment for $30 \mathrm{~min}$. It is worth mentioning that conditioning trials were conducted in an unbiased method such that EtOH/ environment pairings were counterbalanced for the time of EtOH injection (morning or evening) and compartment. Analysis of data from our previous studies using this design (Al Ameri et al. 2014; Al Maamari et al. 2014; Al Mansouri et al. 2014; Bahi 2017a, b; Bahi et al. 2013) showed no difference in the effects of morning vs. evening administration of $\mathrm{EtOH}$ indicating a lack of carryover effects of $\mathrm{EtOH}$ between sessions.

During the post-CPP day, each mouse was individually placed between the two compartments (facing the frame of the guillotine door) with free access to both compartments for $15 \mathrm{~min}$. The expression of EtOH-CPP was calculated as the difference of total time (s) spent in the drug-paired compartment during the post-CPP and the pre-CPP days.

At $24 \mathrm{~h}$ after the CPP-test, mice were given extinction training daily as described previously with minor modifications (Bahi 2012, 2015; Bahi and Dreyer 2014). The procedure was similar to the pre-CPP; all mice were free to access the two chambers for 15 min each day, for 15 days, without any injection. The amount of time that mice spent in each compartment was monitored every other day. The expression of EtOH-CPP extinction was calculated as the difference of total time (s) spent in the drug-paired compartment during the extinction trial and the pre-CPP day. 
The effects of an exposure to the conditioning chambers following stress exposure and housing in a SE or an EE were evaluated as described previously with minor modifications (Bahi 2012, 2015; Bahi and Dreyer 2014). The reinstatement test was the same as that for post-CPP test (free access to both compartments for $15 \mathrm{~min}$ ). The expression of EtOH-CPP reinstatement was calculated as the difference of total time (s) spent in the drug-paired compartment during reinstatement and the last extinction trial.

\section{Chronic psychosocial stress}

The chronic psychosocial stress procedure was developed originally by Reber and colleagues (Reber et al. 2007; Reber et al. 2008) and was performed as described in our previous studies with few modifications (Bahi 2013, 2017b; Bahi and Dreyer 2014). In brief and for 15 days, five experimental subordinate "intruder" mice were introduced into the home cage of larger dominant male mouse "resident" that had been housed with two to three female mice for 7 days to enhance its territoriality and aggression. Males that start to injure their opponents by harmful bites were not used. Being too aggressive, two residents' mice were discarded. To prevent habituation, the five-intruder mice (chronic subordinate colony (CSC)) were weighed and transferred to a novel resident cage in days 5 and 10. In all colonies, the larger male mouse established a dominant status by chasing and attacking all four experimental mice. The intruders were considered as "subordinates" based on their defensive behavior, including flight, retreat, and submissive upright. In parallel, single housed control (SHC) mice remained undisturbed in their home cages except when transferred to clean cages on days 5 and 10 .

\section{Elevated plus maze test}

Both the EPM and OF tests were conducted between 10:00 a.m. and 4:00 p.m. in a brightly lit room that was illuminated with four fluorescent overhead bulb lights, which produce consistent illumination within the room (approximately $100 \mathrm{Lux}$ ). The mice were habituated to the room for $1 \mathrm{~h}$ before starting the respective test.

To evaluate the effect of CSC on anxiety-like behavior, the EPM test was performed as described in our previous studies (Bahi 2017a, b; Bahi and Dreyer 2018, 2019) and originally developed by Pellow et al. (Pellow et al. 1985). In brief, the four-armed wooden EPM apparatus consisted of two open arms $\left(40 \times 6 \times 0.2 \mathrm{~cm}^{3}\right)$ and two closed arms $(40 \times 6 \times$ $\left.20 \mathrm{~cm}^{3}\right)$ facing each other and connected by a central platform $\left(6 \times 6 \mathrm{~cm}^{2}\right)$. The mice were brought into the testing room and allowed to acclimate for $60 \mathrm{~min}$. At the beginning of the test, each mouse was placed in the central area and the number of entries into the open and closed arms (OA and CA respectively) were manually scored during the 5-min test period. After each test, the fecal boli were removed, and the maze was cleaned with a $70 \% \mathrm{EtOH}$ solution to remove odor trails.

\section{Standard and environment enrichment}

The general procedure was performed as described previously with minor modifications (Bahi 2017b). After completion of the EPM test, and like the SHC, CSC mice were single housed in standard Plexiglas cages with regular sawdust bedding and cotton nesting material for SE conditions. Inside each EE cage, and during 15 consecutive days, mice were provided with colorful plastic devices made of LEGO® building bricks, hard paper, cotton nesting material, plastic tube $(15 \mathrm{~cm}$ long and $3 \mathrm{~cm}$ in diameter), and plastic dolls exchanged every week. These objects have been previously used as enriched conditions for mice leading to significant molecular and behavioral differences in laboratory animals (Grinan-Ferre et al. 2018; Hess et al. 2008; Lima and Spinelli de Oliveira 2014; Lopez and Laber 2015).

\section{Open field test}

The OF test was used to evaluate to effect of EE on anxietylike behavior and was performed as previously described (Bahi 2017a, b; Bahi et al. 2014a; Bahi and Dreyer 2012a, $2014,2018,2019)$. In brief, the open field $\left(32 \times 32 \times 20 \mathrm{~cm}^{3}\right)$ Plexiglass square arena was divided into 64 equal squares by black lines. The 16 central squares are regarded as the "center" of the field. Each mouse was placed in the corner of the open field arena and allowed to explore for $10 \mathrm{~min}$. The time spent in the center of the arena, the number of fecal boli produced, and line crossings were scored. After each mouse was tested, the fecal boli produced were counted and removed, and the entire arena was sanitized with $70 \% \mathrm{EtOH}$ to remove odor trails. A low time spent in the center of the arena and high levels of fecal boli production were interpreted as indicators of an anxiogenic-like phenotype (Britton and Britton 1981; Calvo-Torrent et al. 1999; Sanberg 1989).

\section{Experimental design and timeline}

Experiment 1 In this experiment, we tested the effects of EE on CSC-delayed extinction of EtOH-CPP. For this purpose, and after completion of the CPP test (days 1-7), the mice were either single housed (SHC, $n=8$ ) or housed with a dominant male mouse (CSC, $n=20$ ) for 2 weeks (days 8-22). The EPM test was performed $24 \mathrm{~h}$ later (day 23), and the CSC mice were single housed either in SE (CSC-SE, $n=10$ ) or EE (CSC-SE, $\mathrm{n}=10$ ) for 2 weeks (days 24-38). During this period, and in order to induce EtOH-CPP extinction, the mice were exposed daily to the conditioning chambers without any injection and the time spent in the drug-paired box was monitored every other day as described above. It should be emphasized that, 
in this experiment, the OF test was performed on day 30, when the SHC group showed complete EtOH-CPP extinction ( 7 th trial). The experimental timeline is depicted in Fig. 1a.

Experiment 2 In this experiment, we tested the effects of EE on CSC-exacerbated reinstatement of EtOH-CPP after extinction. For this purpose, and after completion of the CPP test (days 1-7), the mice were subjected to eight sessions of CPP extinction (days 8-15). Then, the mice were either single housed (SHC, $n=8$ ) or housed with a dominant male mouse (CSC, $n=20$ ) for 2 weeks (days 16-30) before being tested for anxiety-like behavior using the EPM test (day 31). The CSC mice were then single housed either in SE (CSC-SE, $n=10$ ) or EE (CSC-SE, $n=10$ ) for 2 weeks (days 32-46) and anxiety-like behavior was tested using the OF test (day 47). Twenty-four hours later, all the mice were exposed to the conditioning chambers to reinstate EtOH-CPP (day 48). The experimental timeline is depicted in Fig. $4 \mathrm{a}$.

\section{Statistical analysis}

Statistical analysis was performed using SPSS version 16.0 for Windows. All data are expressed as the mean \pm standard error of the mean. The data representing the effect of stress on body weight gain and anxiety-like behavior in the EPM test were analyzed using one-way measure of variance (ANOVA). The data representing the effects of stress on weight and time on EtOH-CPP extinction were analyzed using one-way repeated measures ANOVA. The data of the EtOH-CPP, area under the curve (AUC) for EtOH-CPP extinction, OF, and EtOH-CPP reinstatement were analyzed using one-way ANOVA. Simple linear regression (Pearson) analysis was performed to examine the correlation between anxiety measures in the EPM test and weight gain after the stress exposure. Also, the same simple linear regression was performed to examine the correlation between anxiety measures in the $\mathrm{OF}$ test after the EE housing with EtOH-CPP extinction (AUC) and reinstatement. The data were checked for homogeneity of the variances with the Levene test. A probability of $p \leq 0.05$ was considered significant. Figures were created with SigmaPlot 11.0.

\section{Results}

\section{Experiment 1-the effects of EE on CSC-delayed extinction of EtOH-CPP}

\section{Two grams per kilogram EtOH can successfully induce EtOH-CPP acquisition in mice}

Although, one mouse was removed from the study due to an initial preference for one of the compartments ( $>80 \%$ of the total session time spent in one compartment), we found no significant overall bias toward either of the compartments during the pre-CPP. In fact, the mice presented no preference for any of the compartments (447.46 vs. $452.54 \mathrm{~s}$ ). However, the repeated administration of EtOH $\left(2 \mathrm{~g} \mathrm{~kg}^{-1}\right)$ produced a preference for the EtOH-paired compartment. One-way ANOVA with repeated measures demonstrated a significant effect of conditioning $\left(F_{(1,27)}=476.814, p<0.0001\right)$ (data not shown). The mice were then randomly assigned to an experimental group (SHC, $n=8$ and CSC, $n=20$ ) as depicted in Fig. 1a.

a

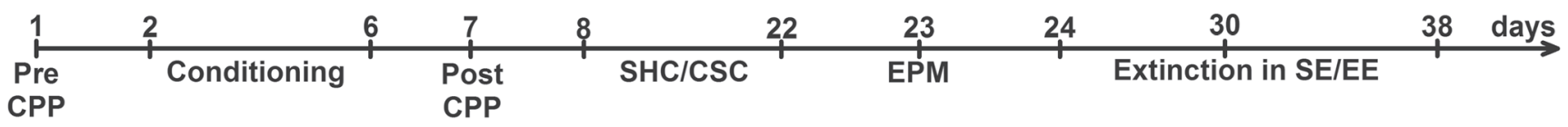

b

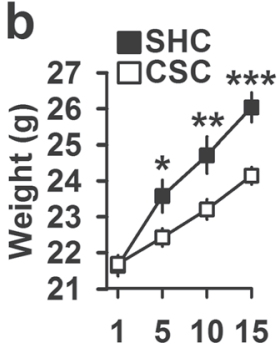

C

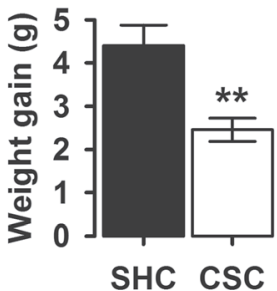

d

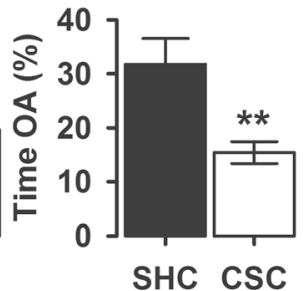

Fig. 1 Experimental timeline, weight gain, and anxiety-like behavior in the EPM test in SHC and CSC mice. a Sequence and duration of experimental protocols of the effects of chronic psychosocial stress and environment on EtOH-CPP extinction. The data are expressed as mean \pm SEM for the $\mathbf{b}$ weight evolution in days $1,5,10$, and 15 of stress exposure, and $\mathbf{c}$ weight gain as the difference in animals' weights between
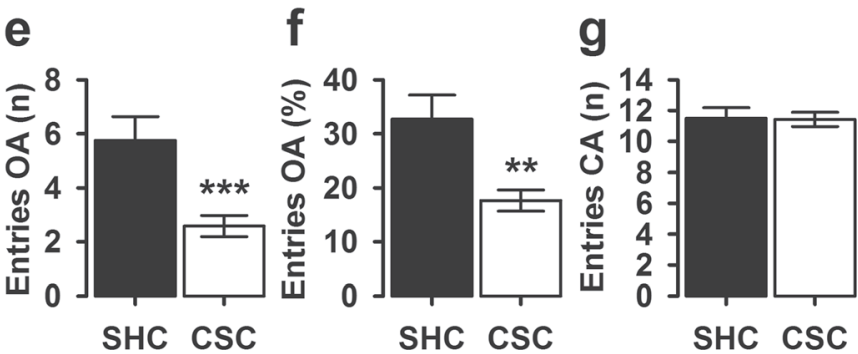

days 1 and 15. For anxiety-like behavior, the data are expressed as mean \pm SEM for the $\mathbf{d}$ percentage of time spent on open arms (OA), e number, $\mathbf{f}$ percentage of entries into the on $\mathrm{OA}$, and $\mathbf{g}$ number of entries into the closed arms (CA). $* p<0.05, * * p<0.005$, and $* * * p<0.0001$ indicate significant differences between SHC and CSC groups. SHC $(n=8)$; CSC $(n=20)$ 


\section{Male CSC mice exhibit reduced weight gain and increased anxiogenic-like behavior}

We have shown that exposure to the CSC stress has been associated with decreased weight gain (Bahi 2013, 2017b; Bahi and Dreyer 2014). Therefore, the SHC and CSC mice were weighed on days $1,5,10$, and 15 to assess the effect of stress on growth. The Levene test revealed that both experimental groups had similar homogeneity (day 1: $F_{(1,26)}=$ $0.065, p=0.800$; day 5: $F_{(1,26)}=0.095, p=0.760$; day 10 : $F_{(1,26)}=0.187, p=0.669$; day 15: $F_{(1,26)}=0.026, p=$ 0.872). As depicted in Fig. 1b, the one-way ANOVA with repeated measures revealed a main effect of time $\left(F_{(3,78)}=\right.$ $75.750, p<0.0001)$ and stress $\left(F_{(1,26)}=9.666, p=0.005\right)$, with a significant interaction between the two factors $\left(F_{(3}\right.$, 78) $=6.336, p=0.001)$. Post hoc analysis indicated that mice in the CSC group had significantly lower body weights at days 5,10 , and $15(p=0.026, p=0.01$, and $p<0.001$, respectively) but not at day $1(p=0.879)$. Consequently, and as depicted in Fig. 1c, extension of this analysis revealed that CSC mice had continued significant weight reduction compared with SHC controls $\left(F_{(1,26)}=13.861, p=0.001\right)$ and the Levene test verified the homogeneity of variance assumption between the two groups $\left(F_{(1,26)}=0.042, p=0.839\right)$.

We and others have shown that CSC exposure in rodents increases anxiogenic-like behavior as assessed by decreased investigation of open areas in a novel environment in the EPM and/or OF tests (Bahi 2013, 2017b; Bahi and Dreyer 2014; Reber et al. 2007). To determine the behavioral consequences of CSC exposure, a series of parameters were measured using the EPM test. The one-way ANOVA revealed that the CSC mice spent significantly less time than SHC controls in the OA of the maze $\left(F_{(1,26)}=15.122, p=0.001\right)$ (Levene test; $F_{(1 \text {, }}$ 26) $=1.921, p=0.177$ ) (Fig. 1d). Similarly, they also entered the OA significantly fewer times than SHC mice $\left(F_{(1,26)}=\right.$ 15.932, $p<0.001$ ) (Levene test; $F_{(1,26)}=3.254, p=0.083$ ) (Fig. 1e) and $\left(F_{(1,26)}=14.176, p=0.001\right)$ (Levene test; $F_{(1,}$ 26 ) $3.473, p=0.074$ ) (Fig. 1f). Finally, and as depicted in Fig. 1g, analysis of total entries in the CA indicated that CSC and SHC mice were equally active $\left(F_{(1,26)}=0.004\right.$, $p=0.953)$ with a homogenic variance between the two groups (Levene test; $F_{(1,26)}=0.192, p=0.665$ ).

It should be emphasized that the Pearson test indicted that CSC-anxiogenic-like behavior correlated with decreased weight gain (data not shown).

\section{EE reduced CSC-anxiogenic-like behavior and CSC-delayed EtOH-CPP extinction}

After completion of the EPM test, the SHC mice were left undisturbed but a cotton nesting material was added to the cage. However, the CSC mice were housed in SE or EE ( $n=10$ each) for 15 days. During this period, the mice were exposed daily to the conditioning chambers to induce EtOHCPP extinction. To be tested for their spontaneous, exploratory locomotion, and anxiety-like behaviors, the mice were subjected to the OF test after the 7th extinction trial (day 30) as described in the "Materials and methods" section.

Before CSC exposure, and as displayed in Fig. 2a, there was no significant differences, in the time spent in the EtOHpaired chamber, between the three experimental groups $\left(F_{(2 \text {, }}\right.$ $25)=0.029, p=0.972)$ and the Levene test verified the homogeneity of the variances $\left(F_{(2,25)}=1.078, p=0.356\right)$.

Analyses of behavioral data collected during OF testing reveled a main effect of housing on the time spent in the center of the arena $\left(F_{(2,25)}=11.932, p<0.0001\right.$; Fig. $\left.2 b\right)$, but the Levene test for variance homogeneity was not found significant $\left(F_{(2,25)}=1.726, p=0.199\right)$. Bonferroni post hoc evaluations revealed that stress exposure resulted in less time spent in the inner area of the field (SHC vs. CSC-SE; $p<0.0001$ ). However, housing in an EE resulted in more time spent in the inner area of the field (CSC-SE vs. CSC-SE; $p=0.018$ ). Also, and as expected, we found a main effect of housing on the number of fecal boli $\left(F_{(2,25)}=11.808, p<0.0001\right.$; Fig. $\left.2 c\right)$, and the equality of variances, using the Levene test, was verified $\left(F_{(2,25)}=0.752, p=0.482\right)$. Bonferroni post hoc evaluations indicated that $\mathrm{CSC}$-SE mice produced more fecal boli in the OF test (SHC vs. CSC-SE; $p<0.0001$ ). However, CSCEE mice defecated less than CSC-SE animals in the novel cages (CSC-SE vs. CSC-SE; $p=0.007$ ). As depicted in Fig. $2 \mathrm{~d}$, the total distance traveled during testing was not altered in the 3 experimental groups $\left(F_{(2,25)}=0.069, p=0.934\right)$. The Levene test verified the homogeneity of variances assumptions $\left(F_{(2,25)}=0.064, p=0.938\right)$.

We have shown in a previous study that CSC mice showed impaired EtOH-CPP extinction (Bahi 2013, 2017b; Bahi and Dreyer 2014). Therefore, in this experiment, we asked whether chronic psychosocial stress-delayed EtOH-CPP extinction can be facilitated "shortened" with EE housing.

During the extinction phase, the mice were placed between the two compartments every day until CPP was extinguished. In fact and as depicted in Fig. 3a, the ANOVA with repeated measures showed significant effect of extinction training $\left(F_{(7}\right.$, $175)=50.007, p<0.0001)$ and housing $\left(F_{(2,25)}=6.317, p=\right.$ $0.006)$ with a significant interaction $\left(F_{(14,175)}=1.926, p=\right.$ 0.026). Bonferroni post hoc evaluations indicated that, compared with SHC, CSC-SE mice showed delayed extinction on days $5,7,9,11$, and 13 ( $p=0.008, p=0.001, p=0.005$, $p<0.001$, and $p=0.028$, respectively). However, EE significantly facilitated EtOH-CPP extinction in CSC mice on days 7 and 11 ( $p=0.027$ and $p=0.004$, respectively) with a strong tendency on day 5 and $9(p=0.084$ and $p=0.067$, respectively). The individual AUC for each group are presented in Fig. 3 b. There was a significant effect of housing on AUC $\left(F_{(2}\right.$, $25)=7.653, p=0.003$ ) with the CSC-SE group experiencing an increase in extinction AUC as compared with the SHC 
Fig. 2 EtOH-CPP expression and anxiety-like behavior in the $\mathrm{OF}$ test in SHC and CSC mice housed in standard (SE) or enriched (EE) environment. The data are expressed as mean \pm SEM for the a EtOH-CPP expression before stress exposure. The data are expressed as mean \pm SEM for the b time spent in the center of the arena, $\mathbf{c}$ number of fecal boli produced, and $\mathbf{d}$ number of line crossings during the $\mathrm{OF}$ test. $* p<$ 0.0001 indicates significant differences between SHC and CSCSE groups. ${ }^{\#} p<0.05$ and ${ }^{\# \#} p<$ 0.01 indicate significant differences between CSC-SE and CSCEE groups. SHC $(n=8)$; CSC-SE $(n=10)$; CSC-EE $(n=10)$

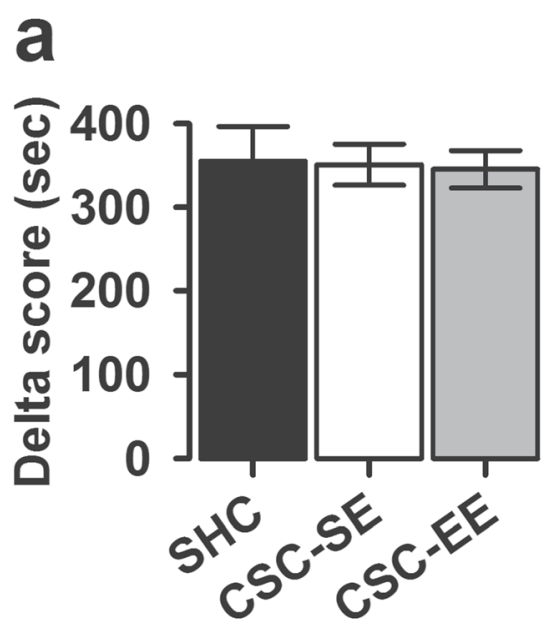

C

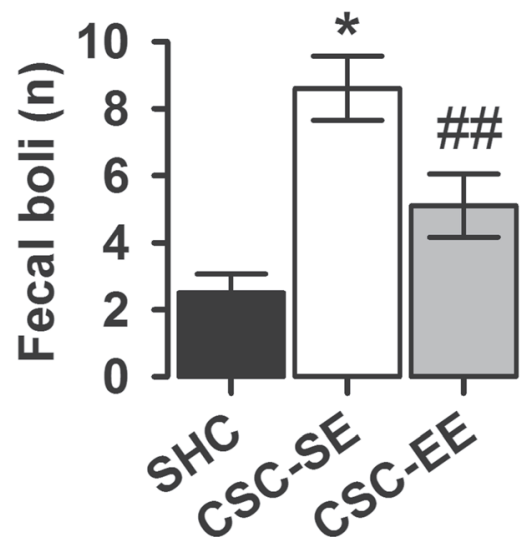

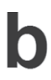

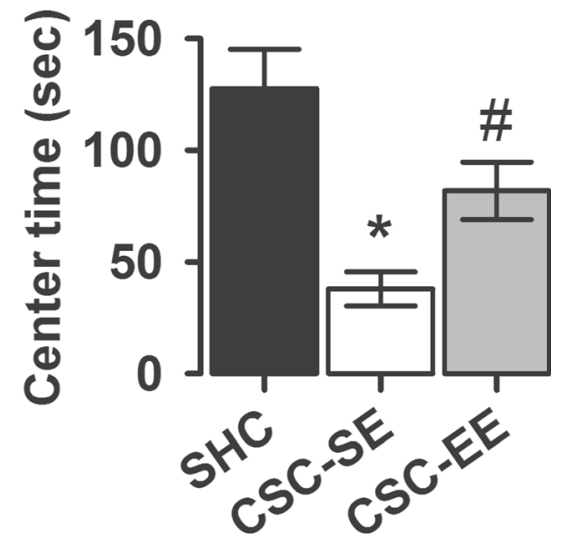

d

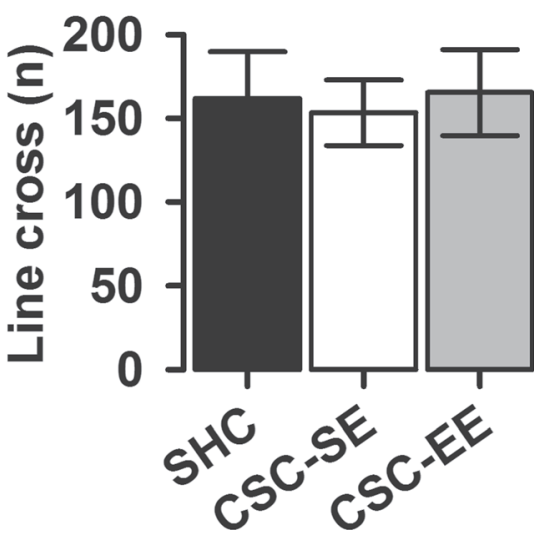

group ( $p=0.001$ ), and the CSC-EE group experiencing a facilitated extinction compared with the CSC-SE group ( $p=$ $0.044)$. The Levene test, used to analyze the homogeneity of variances, was not found significant $\left(F_{(2,25)}=0.276, p=\right.$ 0.761).

A simple linear regression analysis was performed to examine the correlation between the data of anxiety-like behavior obtained from the OF test and the AUC for EtOH-CPP extinction and the results are displayed in Fig. 3. The Pearson analysis showed a significant negative correlation between the AUC and the time spent of the arena $(r=-$ $0.504 ; F_{(1,26)}=8.867, p=0.006$; Fig. $\left.3 \mathrm{c}\right)$. However, the AUC correlated positively with the number of fecal boli produced $\left(r=0.533 ; F_{(1,26)}=10.313, p=0.004 ;\right.$ Fig. $\left.3 \mathrm{~d}\right)$, but not with spontaneous locomotor activity $\left(r=-0.111 ; F_{(1,26)}=\right.$ $0.327, p=0.572$; Data not shown).

Taken together, these results demonstrated that EEdecreased measures of anxiety-like behavior, following CSC exposure, were strongly associated with facilitated "accelerated" EtOH-CPP extinction with no apparent effect on locomotor activity.

\section{Experiment 2-the effects of EE on CSC-impaired EtOH-CPP reinstatement after extinction}

We have shown in a previous report that CSC exposure exacerbated EtOH-CPP reinstatement (Bahi 2013, 2017b; Bahi and Dreyer 2014). Hence, in this experiment, we asked whether, EE can decrease CSC-intensified reinstatement of EtOHCPP after extinction. To this end mice were first conditioned with $2 \mathrm{~g} \mathrm{~kg}^{-1}$ and tested for EtOH-CPP as described above. The timeline of the experiment is displayed in Fig. 4a.

Results have shown that mice displayed no initial preference for any of the compartments ( 451.57 vs. $448.43 \mathrm{~s})$. In addition, the ANOVA with repeated measures indicated that the mice displayed an EtOH-induced preference compared with pre-CPP $\left(F_{(1,27)}=313.814, p<0.0001\right)$ (data not shown). However, there was no significant effect of cohort, indicating that mice displayed similar magnitudes of $\mathrm{CPP}\left(F_{(2}\right.$, ${ }_{25)}=0.009, p=0.991$; Fig. 4b). Then and as displayed in Fig. $4 \mathrm{c}$, the EtOH-CPP was successfully extinguished as indicated by the ANOVA with repeated measures $\left(F_{(7,175)}=81.767\right.$, $p<0.0001$ ), with no significant differences between the three 

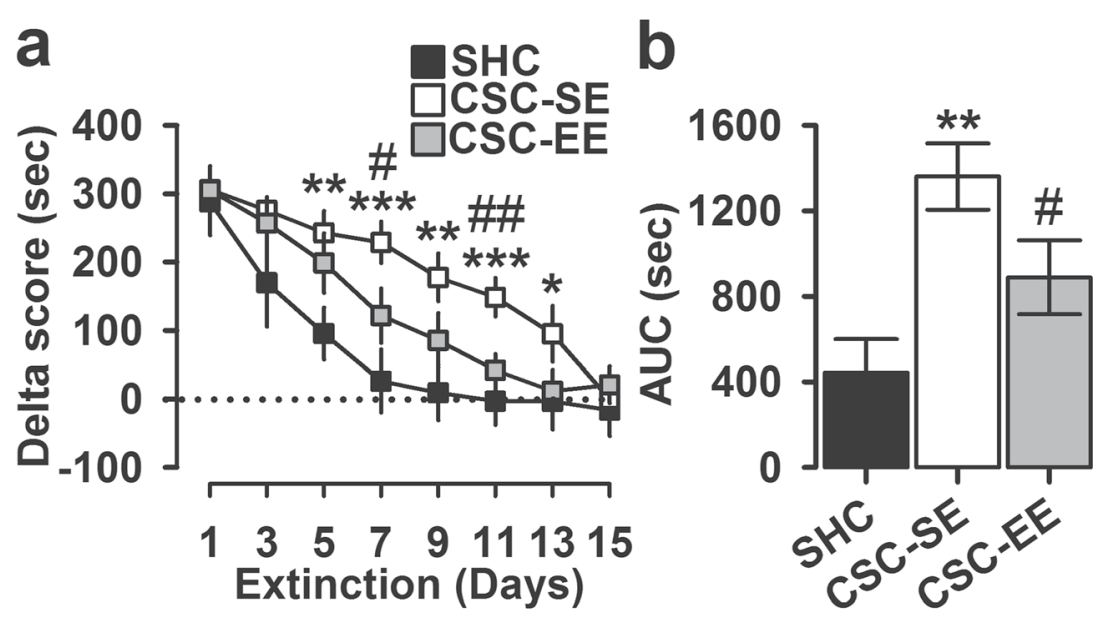

C
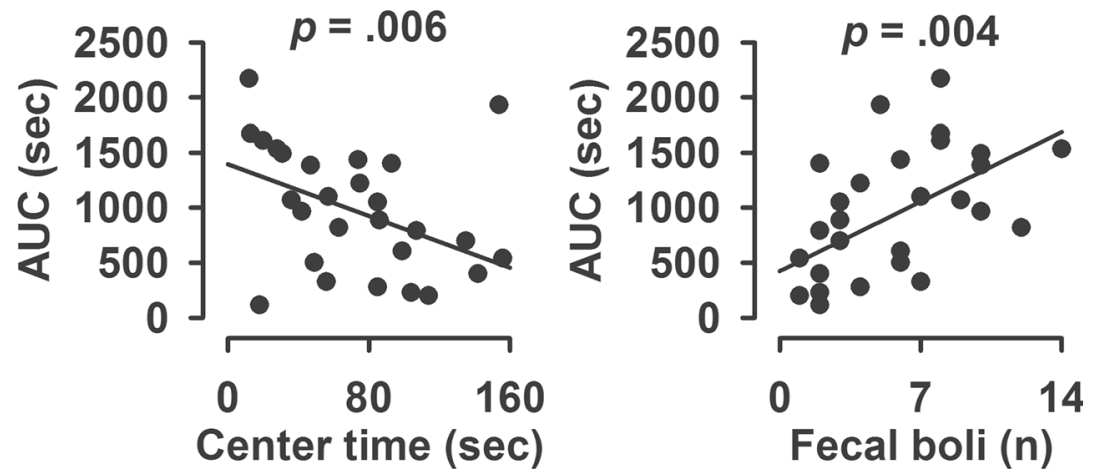

Fig. 3 EtOH-CPP extinction in SHC and CSC mice housed in standard (SE) or enriched (EE) environment and Pearson correlations between area under the curve (AUC) and anxiety-like behavior in the OF test. The data are expressed as mean \pm SEM for the $\mathbf{a}$ extinction of EtOH-CPP and $\mathbf{b}$ AUC for EtOH-CPP extinction. The data represent simple scatter regression between the AUC with $\mathbf{c}$ time spent in the center of the arena and $\mathbf{d}$

number of fecal boli produced during the OF test. $* * * p<0.0001, * * p<$ 0.01 , and $* p<0.05$ indicate significant differences between SHC and CSC-SE groups. ${ }^{\#} p<0.05,{ }^{\# \#} p<0.01$, and ${ }^{\# \# \#} p<0.005$ indicate significant differences between CSC-SE and CSC-EE groups. SHC $(n=8)$;

CSC-SE $(n=10)$; CSC-EE $(n=10)$

a

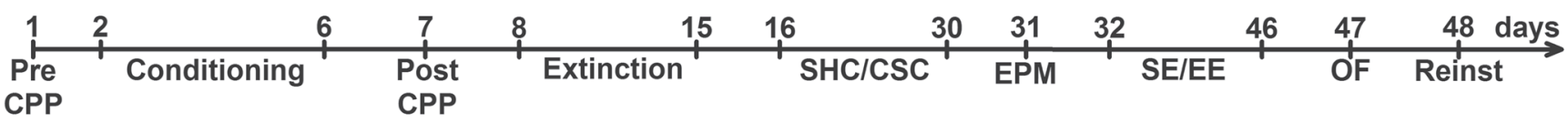

b

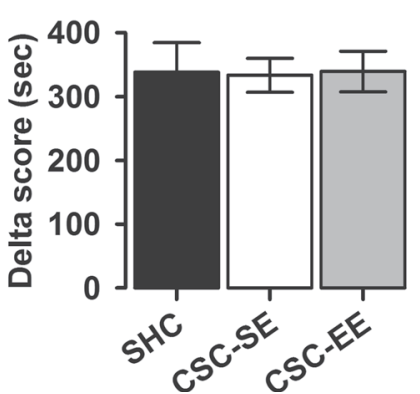

C

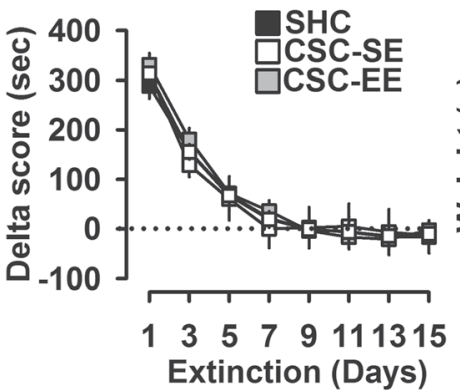

Fig. 4 Experimental timeline, EtOH-CPP expression and extinction, and weight gain in SHC and CSC mice. a Sequence and duration of experimental protocols of the effect of chronic psychosocial stress and environment on EtOH-CPP reinstatement after extinction. The data are expressed as mean \pm SEM for the $\mathbf{b}$ EtOH-CPP expression and $\mathbf{c}$ extinction. The d

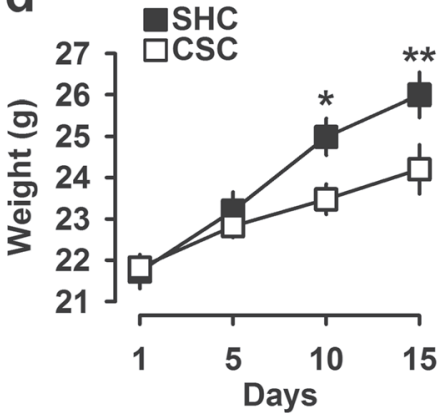

e

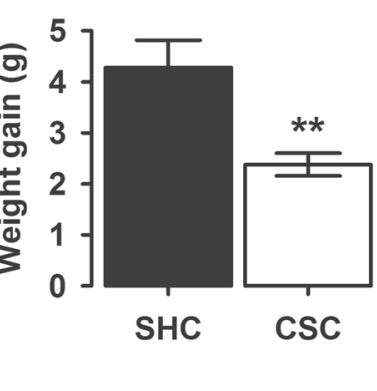

data are expressed as mean \pm SEM for the $\mathbf{d}$ weight evolution in days 1,5 , 10 , and 15 of stress exposure and $\mathbf{e}$ weight gain as the difference in animals' weights between days 1 and $15 . * p<0.01$ and $* * p<0.005$ indicate significant differences between SHC and CSC groups. SHC $(n=8) ; \operatorname{CSC}(n=20)$ 
cohorts $\left(F_{(2,25)}=0.063, p=0.939\right)$. The differences of the AUC of EtOH-CPP extinction for the three cohorts were not found significant $\left(F_{(2,25)}=0.045, p=0.956\right.$; data not shown).

\section{After extinction, chronic psychosocial stress reduced weight gain and increased anxiogenic-like behavior}

After EtOH-CPP extinction, cohorts of mice $(n=20)$ were housed with a dominant mouse for 15 days. According to the Levene test, the groups had similar homogeneity at all time points in term of weight gain (day 1: $F_{(1,26)}=1.059, p=$ 0.313 ; day $5: F_{(1,26)}=0.171, p=0.682$; day $10: F_{(1,26)}=$ $0.248, p=0.623$; day $\left.15: F_{(1,26)}=0.467, p=0.501\right)$. As expected, the ANOVA with repeated measures revealed a main effect of time on body growth performance $\left(F_{(3,78)}=81.949\right.$, $p<0.0001$ ), and the mice exposed to 2 weeks of CSC gained significantly less weight than those in the SHC group $\left(F_{(1}\right.$, $\left.{ }_{26)}=4.928, p=0.035\right)$ with a significant time $\times$ stress interaction $\left(F_{(3,78)}=7.943, p<0.0001\right)$ (Fig. 4d). Bonferroni post hoc evaluations indicated that CSC mice showed less weight after 10 and 15 days of stress $(p=0.006$ and $p=0.003$ respectively), but not after 5 days $(p=0.478)$. Also and as displayed in Fig. 4e, the animals in the CSC model group displayed significantly reduced body weight gain $\left(F_{(1,26)}=15.249\right.$, $p=0.001$ ) with the variance homogeneity distribution checked by the Levene test $\left(F_{(1,26)}=1.784, p=0.193\right)$.
The mice were then tested for their anxiety-like behavior using the EPM test and results indicated that chronic psychosocial stress increased anxiety, as evidenced by decreased time spent on the OA of the maze $\left(F_{(1,26)}=25.420, p<0.0001\right)$ (Levene test: $F_{(1,26)}=0.005, p=0.942$ ) (Fig. 5a). The CSC mice displayed less number $\left(F_{(1,26)}=27.351, p<0.0001\right.$; Fig. $5 b)$ and percentage $\left(F_{(1,26)}=16.038, p<0.0001\right.$; Fig. $\left.5 c\right)$ of entries in the OA with the homogeneity of variances assumptions being verified by the Levene test for both parameters $\left(\left(F_{(1,26)}=0.004, p=0.952\right)\right.$ and $\left(F_{(1,26)}=2.570, p=0.121\right)$, respectively). Lastly and as depicted in Fig. 5d, we demonstrated that stress exposure had no effect on spontaneous locomotor activity as $\mathrm{SHC}$ and CSC mice showed equal number of visits to the CA of the $\operatorname{EPM}\left(F_{(1,26)}=0.114, p=0.739\right)$ (Levene test for homogeneity of variance between the two groups, $F_{(1,26)}=1.373, p=0.252$ ).

The relationship between weight gain and anxiety-like behavior was explored through Pearson correlation analysis and the results indicated that CSC-anxiogenic-like behavior correlated with decreased weight gain the (data not shown).

\section{EE ameliorated CSC-induced anxiety-like behavior and reduced EtOH-CPP reinstatement}

After the EPM test, the CSC mice were housed in SE or EE for 15 days and anxiety-like behavior was tested using the $\mathrm{OF}$ test
Fig. 5 Anxiety-like behavior in the EPM test in SHC and CSC mice. The data are expressed as mean \pm SEM for the a percentage of time spent on open arms (OA), b number, $\mathbf{c}$ percentage of entries into the on $\mathrm{OA}$, and $\mathbf{d}$ number of entries into the closed arms (CA). $* p<0.001$ indicates significant differences between SHC and CSC groups. SHC $(n=8)$; CSC $(n=20)$
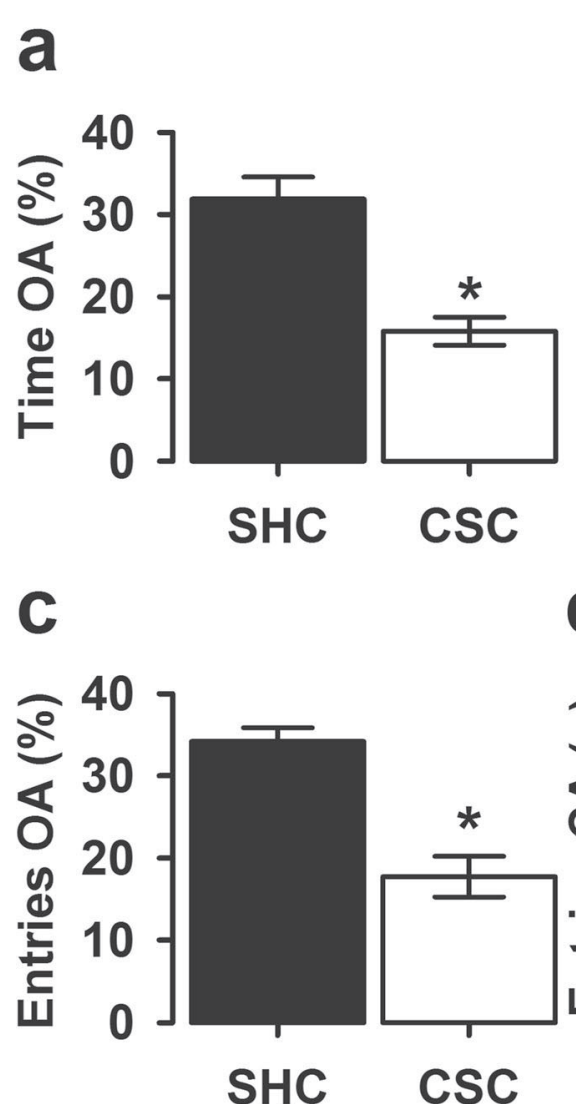

b
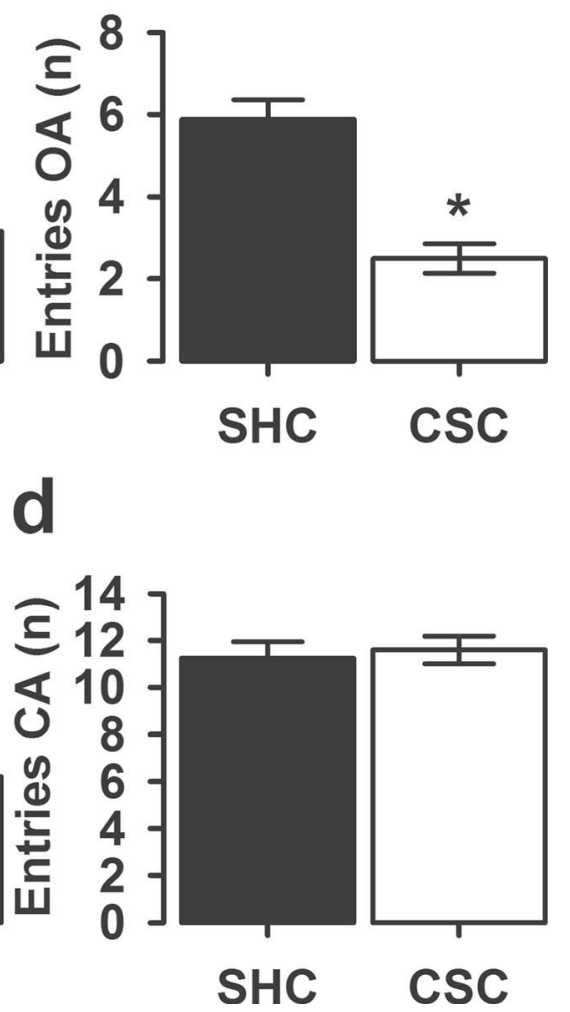
and the results are displayed in Fig. 6. As expected, there was main effect of housing on the time spent in the center of the arena $\left(F_{(2,25)}=10.187, p=0.001\right)$. In fact, as depicted in Fig. $6 \mathrm{a}$, compared with the SHC controls, chronic stress exposure significantly shortened the time the mice spent in the center of the OF $(p<0.0001)$. However, post hoc evaluations comparing CSC-SE and CSC-EE showed higher responses by the latter in center squares time $(p=0.031)$ with equal variances (Levene test: $\left.F_{(2,25)}=2.979, p=0.069\right)$. Also, 15-day stress exposure affected the number of fecal boli $\left(F_{(2,25)}=11.325\right.$, $p<0.001$ ) (Fig. 6b) and the homogeneity of variances was verified with the Levene test $\left(F_{(2,25)}=2.772, p=0.082\right)$. Bonferroni post hoc evaluations indicated that CSC mice housed in SE produced more fecal boli during the OF test than SHC mice $(p<0.001)$. However, CSC-EE shed fewer fecal boli than CSC-SE mice in the OF $(p=0.050)$. As shown in Fig. 6c, neither the CSC nor the EE affected spontaneous locomotor activity $\left(F_{(2,25)}=0.213, p=0.810\right)$ (Levene test: $\left.F_{(2,25)}=0.148, p=0.863\right)$.

a
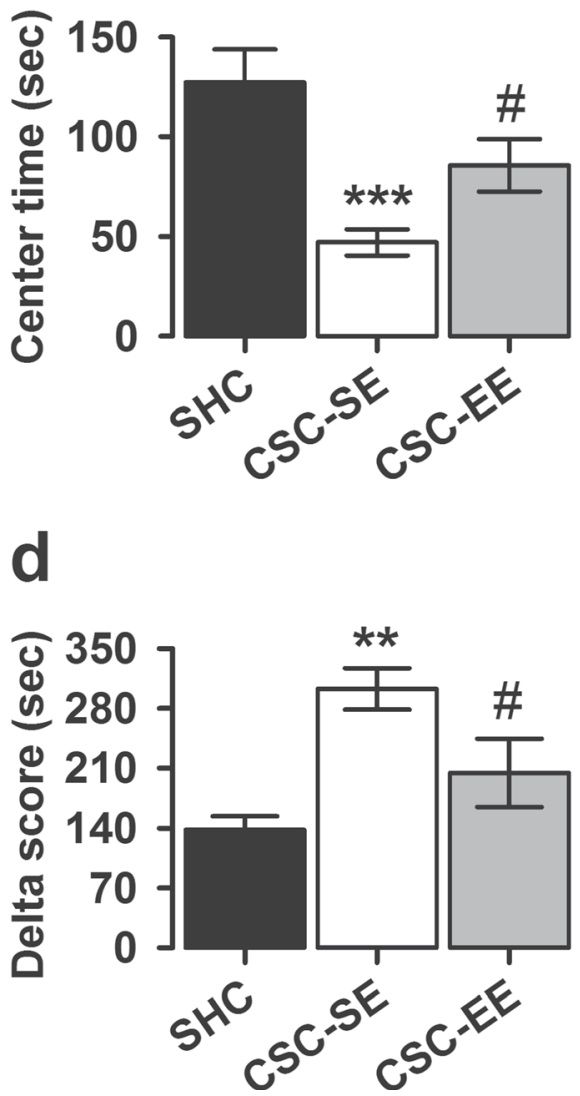

e

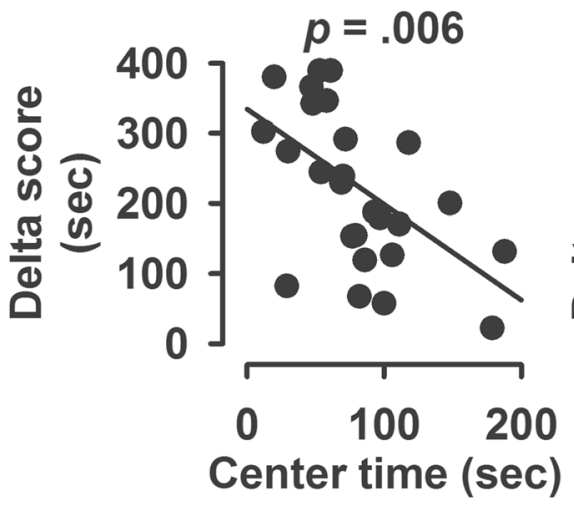
b c

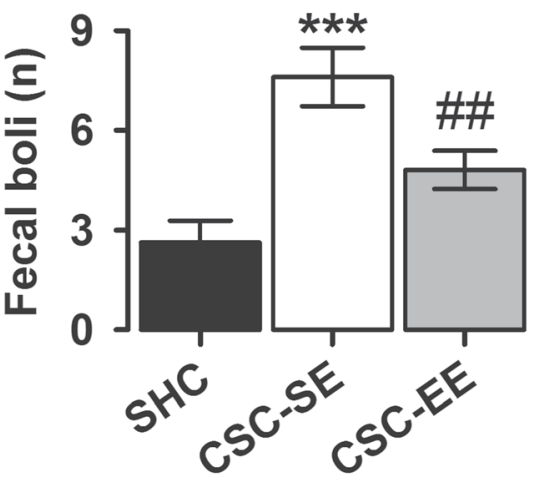

We next examined how EE- and CSC-resulted memory retrieval disruption influences subsequent $\mathrm{EtOH}$-induced reinstatement of the CPP. In this test, the animals spent significantly more time in the drug-paired compartment when compared with the last extinction session $\left(F_{(1,27)}=94.862\right.$, $p<0.0001)$ with a significant effect of housing $\left(F_{(2,25)}=\right.$ 5.786, $p=0.009$ ) (Fig. 6d) and nonsignificant Levene test $\left(F_{(2,25)}=0.548, p=0.585\right)$. Bonferroni post hoc analysis showed that, as expected, in a SE, CSC exacerbated EtOHCPP reinstatement ( $p=0.003$ vs. SHC). However, the CPP reinstatement, observed in the mice housed in an EE, was significantly lower compared with the CPP reinstatement observed in the mice housed in a SE $(p=0.028)$.

Taken together, EE induced a significant deficit in $\mathrm{EtOH}-$ associated memory retrieval as CSC-increased reinstatement was considerably decreased by EE.

Lastly, a Pearson correlation test to determine the strength of association between EtOH-CPP reinstatement and anxietylike behavior in the OF test showed a strong negative

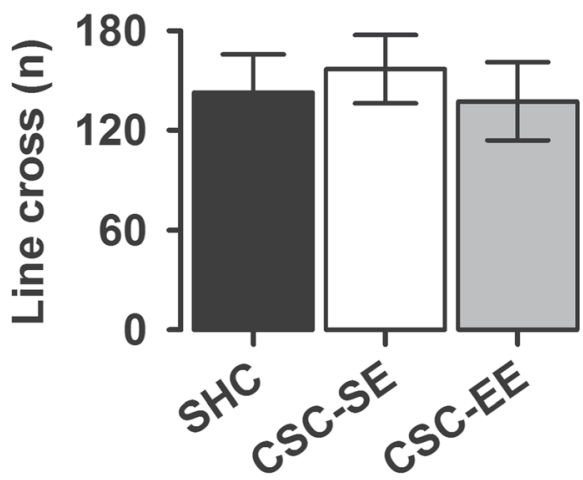

Fig. 6 Anxiety-like behavior in the OF test, EtOH-CPP reinstatement in SHC, and CSC mice housed in SE or EE and Pearson correlations. The data are expressed as mean $\pm \mathrm{SEM}$ for the a time spent in the center of the arena, $\mathbf{b}$ number of fecal boli produced, and $\mathbf{c}$ number of line crossings during the OF test. The data are expressed as mean \pm SEM for the $\mathbf{d}$ EtOH-CPP reinstatement CPP in SHC and CSC housed in SE or EE. The data represent simple scatter regression between EtOH-CPP reinstatement with e time spent in the center of the arena and $\mathbf{f}$ number of fecal boli produced during the OF test. $* * * p<0.0001, * * p<0.001$, and $* p<0.005$ indicate significant differences between SHC and CSCSE groups. ${ }^{\#} p<0.05$ and ${ }^{\# \#} p<0.01$ indicate significant differences between CSC-SE and CSC-EE groups. SHC $(n=8)$; CSC-SE $(n=10)$; CSC-EE $(n=10)$ 
correlation between CPP reinstatement and the time spent in the center of the arena $\left(r=-0.611, F_{(1,26)}=15.493, p=\right.$ 0.001 ; Fig. $6 \mathrm{e}$ ), and a moderate, yet significant positive correlation between reinstatement and defecation in the OF $(r=$ $0.469, F_{(1,26)}=7.339, p=0.012$; Fig. 6f). However, both linear regression and Pearson correlations demonstrated no significant relationship between CPP reinstatement and line crossings, i.e., spontaneous locomotor activity $(r=0.187$, $F_{(1,26)}=0.944, p=0.340$; data not shown).

The results indicated that EE-decreased reinstatement of EtOH-CPP could be correlated with EE-anxiolytic-like effect.

\section{Discussion}

To the best of our knowledge, the present study is the first to investigate the effects of EE following chronic psychosocial stress on EtOH-CPP extinction and reinstatement. Indeed, two major findings arise from the current investigation. First, we found that stress-delayed EtOH-CPP extinction was facilitated upon exposure to an EE. Second, when EtOH-CPP was extinguished, EE blocked EtOH-CPP reinstatement.

In agreement with previous studies from our laboratory (Bahi 2013, 2017b; Bahi and Dreyer 2014), the data presented in the current study provide strong indication that subordinate colony housing (CSC) is a suitable procedure to model chronic psychosocial stress in male mice. As expected, we have observed that stress exposure induced a significant reduction in body weight gain which is in line with our previous reports (Bahi 2013, 2017b; Bahi and Dreyer 2014) and with others using the same model (Fuchsl et al. 2014; Nyuyki et al. 2012; Reber et al. 2007; Reber et al. 2008; Singewald et al. 2009; Slattery et al. 2012; Veenema et al. 2008). Moreover, repeated defeat (once a day for 7 days) decreased body weight gain in Lewis rats in a time-dependent manner (Berton et al. 1998). It has been shown in rats that the extent of body weight gain is related to the rank of the animal within a social group (Stefanski 2001). In mice, several studies have reported that subordinate males are characterized by severe and significant weight loss (Blanchard et al. 1995; Tamashiro et al. 2004). One possible explanation is that weight loss in subordinate mice during social stress was due to the loss of adipose tissue. In fact, previous data have shown that while subordinate mice lost adipose tissue during stress exposure, they retained a higher percentage of visceral fat compared with controls (Tamashiro et al. 2007). Although, visceral fat is known to be an important risk factor in the development of different signs of the metabolic syndrome (for review, see (Eckel et al. 2005)), the mechanisms contributing to its development are not well characterized and more research is needed to elucidate such mechanisms.

We also observed that exposure to CSC significantly increased anxiety-like behavior as indicated by a decrease in the percentage of time spent on the open arms, and in the percentage of open arm entries compared with control mice. The number of entries into the closed arms, indicative of spontaneous locomotor activity, was not affected by CSC exposure as we have reported in our previous studies (Bahi 2013, 2017b; Bahi and Dreyer 2014). The current results are in line with previous studies showing that prolonged periods of stress result in higher anxiety levels. In fact, elevated level of anxiety is a strong indicator of acute or chronic stress because restraint (1 h) produced an anxiogenic-like phenotype in the elevated X-maze (McBlane and Handley 1994). In rats, exposure to the aggressive resident, leading to the rapid social defeat of the intruder, reduced subsequent exploration of open maze arms in males (Heinrichs et al. 1992; Nephew and Bridges 2011; Rygula et al. 2008) and females (McCormick et al. 2008). Similarly, in male DBA/2 mice, defeat by an experienced aggressive conspecific dominant mouse enhanced anxiety as indicated by decreases in percent open arm entries and percent time spent on the open arms (Rodgers and Cole 1993). Also, in DBA/2OlaHsd mice, chronic social defeat induced an increased avoidance behavior and significant reduction in directed exploration, and general exploration, as well as locomotion (Erhardt et al. 2009). Taken together, the findings confirmed stress vulnerability for subordinate mice and further establish the strength to use the current CSC procedure as a model for anxiety-related disorders.

In the 1st experiment, we asked the question whether EE could reverse and accelerate stress-delayed EtOH-CPP extinction. EtOH $\left(2 \mathrm{~g} \mathrm{~kg}^{-1}\right)$ elicited a reliable and consistent CPP response. In fact, and after a period of conditioning, the mice spent significantly more time in the chamber paired with EtOH. These results are consistent with earlier studies, from our laboratory (Al Ameri et al. 2014; Al Maamari et al. 2014; Bahi and Dreyer 2014; Bahi et al. 2014b) and from others, in which $2 \mathrm{~g} \mathrm{~kg}^{-1}$ EtOH elicited a robust CPP in both mice (Huang et al. 2018; Marcus et al. 2017; Xie et al. 2019), and rats (Fu et al. 2016; Okhuarobo et al. 2018; Zuo et al. 2017). Next, we found, in the 1 st experiment, that repeated daily exposure to both conditioning chambers successfully extinguished this CPP. It is interesting to note that, in control animals (SHC group), only 7 to 8 consecutive days were required to produce a reliable extinction. However, when mice were housed in a SE, after being exposed to chronic social stress (CSC-SE group), CPP extinction was significantly delayed and was achieved only after 14 days of repeated exposure to the conditioning chambers. Most importantly, EE accelerated EtOH-CPP extinction by 4-5 days in stress-exposed mice. In the 2nd experiment, we observed that, following extinction, EE attenuated stress-induced EtOH-CPP reinstatement.

It is worth mentioning that an experimental group receiving no social stress followed by EE is lacking from this study. Therefore, we should acknowledge that without such a 
control, we cannot rule out the general effects of EE on learning and motivation, rather than effects specific to EtOH-CPP, or drug reward in general. Nevertheless, the current findings confirm and extend a large body of literature that utilized selfadministration, as well as CPP, to show that EE could reverse stress- and drug-elicited reinstatement following extinction with other drugs of abuse and psychostimulants. In fact, Gauthier et al. (2017) have reported that brief periods of EE programmed at appropriate times in combination with cocaine-cue extinction sessions facilitated extinction and prevented subsequent reacquisition of cocaine selfadministration in male Wistar rats. Also, EE attenuated cocaine-seeking behavior compared with isolated conditions in rats (Thiel et al. 2012). Similarly, the effects of EE on nicotine-induced CPP in male rats were assessed and the results indicated that, in enriched conditions, rats showed extinction of the nicotine-induced CPP response by the 5th extinction session (Ewin et al. 2015). Also, while animals in standard and enriched housing conditions intravenously selfadministered similar amounts of heroin over 14 days, EE diminished extinction response in male Sprague-Dawley rats (Imperio et al. 2018). In addition, 30 days of EE significantly and consistently reduced cocaine seeking behavior during extinction sessions and significantly reduced cue and stressinduced reinstatement of cocaine self-administration (Chauvet et al. 2009).

It should be emphasized that chronic social stress decreased body weight in these animals by $10-15 \%$. Such dramatic changes could lead to alterations in motivational mechanisms generally. In fact, a growing body of literature suggested that food restriction following CPP training enhances CPP reinstatement. For example, unlike those tested under the ad libitum feeding condition, food restricted rats showed a persistent cocaine-CPP (Zheng et al. 2012). Similarly, rats that were food restricted displayed a strong increase in cue-induced heroin seeking behavior and, interestingly, refeeding prior to testing or shortening the food restriction duration abrogated the increase of heroin seeking behavior (D'Cunha et al. 2013). Moreover, foodrestricted rats performed significantly more active lever presses and earned more sucrose reinforcements than ad libitum fed rats (Cason and Aston-Jones 2014). Also, a mild food restriction regimen, that results in the rats' body weights maintained at $90 \%$ of their nonrestricted body weight, resulted in a significantly increased rates of heroin seeking on test day (Sedki et al. 2013a; b). In the light of these findings, we cannot exclude that weight loss is still a potential cause of enhanced EtOH-CPP reinstatement and delayed extinction. Similarly, the amelioration of that weight loss might cause a reduction of CPP reinstatement seen following EE. Although earlier studies had focused on the "protective/preventive" effects of EE, it has been reported that EE can also have "curative/restorative" effects on psychostimulants' addiction as cocaine-induced CPP was sustained over long periods of abstinence in mice housed in SE but is gone in mice housed in EE (Solinas et al. 2008). Taken together, these findings indicate that EE can accelerate CPP extinction and remove already established addiction-related behaviors in rodents and suggest that EE may be an important aspect in facilitating abstinence and preventing relapse to EtOH addiction.

Although the current investigation demonstrates the ability of EE to facilitate CPP extinction and reduce stress-triggered EtOH-CPP reinstatement, it limits insight into the possible mechanisms underlying this effect. Nevertheless, we speculate that EE enhanced extinction learning, as suggested previously for EE effects on reducing cue-elicited sucrose-seeking behavior (Grimm et al. 2008). Indeed, EE improves learning on a number of behavioral task measures such as spatial learning, reinforcement, place preference, and discrimination tasks (Bardo et al. 1995; Pham et al. 1999; Rosenzweig and Bennett 1996; Smith et al. 2005; van Praag et al. 2000). Therefore, we hypothesize that, following stress exposure, EE mice may have learned more quickly that EtOH-associated cues no longer predicted $\mathrm{EtOH}$ administration, suggesting that $\mathrm{EE}$ might attenuate the incentive motivational effects of the EtOH-paired stimuli. It should be emphasized that this explanation might not be totally in line with Chauvet et al.'s (2009) findings which indicated that EE blunts cocaineseeking behavior on the 1st day of extinction, and afterward throughout re-exposure, without seeming to facilitate extinction learning (i.e., rate of extinction across days) per se. On another hand, a large body of evidence suggested that the rewarding effects of EtOH are due to increases in dopamine levels in the mesolimbic system (Di Chiara 1997), indicating that dopaminergic neurotransmission is a critical factor in both drug reward and relapse. Therefore, it seems that EE might "protect" against subsequent increases in brain dopamine elicited by stress exposure. In fact, stressincreased dopamine release in the prefrontal cortex (PFC) was significantly lower in enriched animals when compared with controls (Segovia et al. 2008). Also, handling-induced dopamine release in the PFC was significantly reduced in an EE (Segovia et al. 2008), suggesting that EE might reduce the activity of the mesocortical dopaminergic system. Regardless of the mechanisms underlying these effects, the implications of this study offer promise for alcohol-dependent individuals.

In conclusion, following stress exposure, EE facilitates extinction and reduces the risk of relapse in mice. Although, caution must be taken when generalizing these results to a human population, these findings highlight how environmental situations of people looking to quit drug taking could possibly contribute to the positive result of their efforts. In fact, studies in which different forms of stimulation have been used were shown to be useful for the treatment of addiction (Schnabel 2009). Therefore, the use of environmental 
stimulation together with pharmacotherapy as well as behavioral therapy may be of fundamental importance in the achievement of effective alcoholism treatment programs.

Acknowledgments The authors would like to acknowledge Mr. Mohamed Shafiullah for his technical assistance and Dr. Mahmoud Hag Ali from the Central Animal Facility for his advice on animal care and welfare. The authors thank the three anonymous reviewers whose comments and suggestions have greatly improved this manuscript.

Funding information $\mathrm{AB}$ was supported by grants from the United Arab Emirates University (No. NP/13/05) and the National Research foundation (No. 31M082). The funders had no further role in study design; in the collection, analysis, and interpretation of data; in the writing of the report; and in the decision to submit the paper for publication.

\section{Compliance with ethical standards}

Conflict of interest The authors declare that they have no conflict interest.

\section{References}

Al Ameri M, Al Mansouri S, Al Maamari A, Bahi A (2014) The histone deacetylase (HDAC) inhibitor valproic acid reduces ethanol consumption and ethanol-conditioned place preference in rats. Brain Res 1583:122-131

Al Maamari E, Al Ameri M, Al Mansouri S, Bahi A (2014) Inhibition of urokinase plasminogen activator "uPA" activity alters ethanol consumption and conditioned place preference in mice. Drug Des Devel Ther 8:1391-1403

Al Mansouri S, Ojha S, Al Maamari E, Al Ameri M, Nurulain SM, Bahi A (2014) The cannabinoid receptor 2 agonist, beta-caryophyllene, reduced voluntary alcohol intake and attenuated ethanol-induced place preference and sensitivity in mice. Pharmacol Biochem Behav 124:260-268

Albrechet-Souza L, Viola TW, Grassi-Oliveira R, Miczek KA, de Almeida RMM (2017) Corticotropin releasing factor in the bed nucleus of the stria terminalis in socially defeated and non-stressed mice with a history of chronic alcohol intake. Front Pharmacol 8: 762

Arai JA, Feig LA (2011) Long-lasting and transgenerational effects of an environmental enrichment on memory formation. Brain Res Bull 85:30-35

Bahi A (2012) The selective metabotropic glutamate receptor 7 allosteric agonist AMN082 prevents reinstatement of extinguished ethanolinduced conditioned place preference in mice. Pharmacol Biochem Behav 101:193-200

Bahi A (2013) Increased anxiety, voluntary alcohol consumption and ethanol-induced place preference in mice following chronic psychosocial stress. Stress 16:441-451

Bahi A (2015) The oxytocin receptor impairs ethanol reward in mice. Physiol Behav 139:321-327

Bahi A (2017a) Decreased anxiety, voluntary ethanol intake and ethanolinduced CPP acquisition following activation of the metabotropic glutamate receptor 8 "mGluR8". Pharmacol Biochem Behav 155: $32-42$

Bahi A (2017b) Environmental enrichment reduces chronic psychosocial stress-induced anxiety and ethanol-related behaviors in mice. Prog Neuro-Psychopharmacol Biol Psychiatry 77:65-74
Bahi A, Dreyer JL (2012a) Hippocampus-specific deletion of tissue plasminogen activator "tPA" in adult mice impairs depression- and anxiety-like behaviors. Eur Neuropsychopharmacol 22:672-682

Bahi A, Dreyer JL (2012b) Involvement of tissue plasminogen activator "tPA" in ethanol-induced locomotor sensitization and conditionedplace preference. Behav Brain Res 226:250-258

Bahi A, Dreyer JL (2014) Chronic psychosocial stress causes delayed extinction and exacerbates reinstatement of ethanol-induced conditioned place preference in mice. Psychopharmacology 231:367-377

Bahi A, Dreyer JL (2018) Lentiviral-mediated let-7d microRNA overexpression induced anxiolytic- and anti-depressant-like behaviors and impaired dopamine D3 receptor expression. Eur Neuropsychopharmacol 28:1394-1404

Bahi A, Dreyer JL (2019) Dopamine transporter (DAT) knockdown in the nucleus accumbens improves anxiety- and depression-related behaviors in adult mice. Behav Brain Res 359:104-115

Bahi A, Tolle V, Fehrentz JA, Brunel L, Martinez J, Tomasetto CL, Karam SM (2013) Ghrelin knockout mice show decreased voluntary alcohol consumption and reduced ethanol-induced conditioned place preference. Peptides 43:48-55

Bahi A, Al Mansouri S, Al Memari E, Al Ameri M, Nurulain SM, Ojha S (2014a) Beta-Caryophyllene, a CB2 receptor agonist produces multiple behavioral changes relevant to anxiety and depression in mice. Physiol Behav 135:119-124

Bahi A, Nurulain SM, Ojha S (2014b) Ethanol intake and ethanolconditioned place preference are reduced in mice treated with the bioflavonoid agent naringin. Alcohol 48:677-685

Bardo MT, Bowling SL, Rowlett JK, Manderscheid P, Buxton ST, Dwoskin LP (1995) Environmental enrichment attenuates locomotor sensitization, but not in vitro dopamine release, induced by amphetamine. Pharmacol Biochem Behav 51:397-405

Berton O, Aguerre S, Sarrieau A, Mormede P, Chaouloff F (1998) Differential effects of social stress on central serotonergic activity and emotional reactivity in Lewis and spontaneously hypertensive rats. Neuroscience 82:147-159

Blanchard DC, Spencer RL, Weiss SM, Blanchard RJ, McEwen B, Sakai RR (1995) Visible burrow system as a model of chronic social stress: behavioral and neuroendocrine correlates. Psychoneuroendocrinology 20:117-134

Britton DR, Britton KT (1981) A sensitive open field measure of anxiolytic drug activity. Pharmacol Biochem Behav 15:577-582

Calvo-Torrent A, Brain PF, Martinez M (1999) Effect of predatory stress on sucrose intake and behavior on the plus-maze in male mice. Physiol Behav 67:189-196

Caruso MJ, Seemiller LR, Fetherston TB, Miller CN, Reiss DE, Cavigelli SA, Kamens HM (2018) Adolescent social stress increases anxietylike behavior and ethanol consumption in adult male and female C57BL/6J mice. Sci Rep 8:10040

Cason AM, Aston-Jones G (2014) Role of orexin/hypocretin in conditioned sucrose-seeking in female rats. Neuropharmacology 86:97102

Chauvet C, Lardeux V, Goldberg SR, Jaber M, Solinas M (2009) Environmental enrichment reduces cocaine seeking and reinstatement induced by cues and stress but not by cocaine. Neuropsychopharmacology 34:2767-2778

Cloutier RM, Blumenthal H, Trim RS, Douglas ME, Anderson KG (2019) Real-time social stress response and subsequent alcohol use initiation among female adolescents. Psychol Addict Behav 33:254 265

Conway KP, Compton W, Stinson FS, Grant BF (2006) Lifetime comorbidity of DSM-IV mood and anxiety disorders and specific drug use disorders: results from the National Epidemiologic Survey on alcohol and related conditions. J Clin Psychiatry 67:247-257

D'Cunha TM, Sedki F, Macri J, Casola C, Shalev U (2013) The effects of chronic food restriction on cue-induced heroin seeking in abstinent male rats. Psychopharmacology 225:241-250 
Di Chiara G (1997) Alcohol and dopamine. Alcohol Health Res World 21:108-114

Eckel RH, Grundy SM, Zimmet PZ (2005) The metabolic syndrome. Lancet 365:1415-1428

El Rawas R, Thiriet N, Lardeux V, Jaber M, Solinas M (2009) Environmental enrichment decreases the rewarding but not the activating effects of heroin. Psychopharmacology 203:561-570

Erhardt A, Muller MB, Rodel A, Welt T, Ohl F, Holsboer F, Keck ME (2009) Consequences of chronic social stress on behaviour and vasopressin gene expression in the PVN of DBA/2OlaHsd miceinfluence of treatment with the CRHR1-antagonist R121919/NBI 30775. J Psychopharmacol 23:31-39

Ewin SE, Kangiser MM, Stairs DJ (2015) The effects of environmental enrichment on nicotine condition place preference in male rats. Exp Clin Psychopharmacol 23:387-394

Fu R, Chen X, Zuo W, Li J, Kang S, Zhou LH, Siegel A, Bekker A, Ye JH (2016) Ablation of mu opioid receptor-expressing GABA neurons in rostromedial tegmental nucleus increases ethanol consumption and regulates ethanol-related behaviors. Neuropharmacology 107: $58-67$

Fuchsl AM, Neumann ID, Reber SO (2014) Stress resilience: a lowanxiety genotype protects male mice from the consequences of chronic psychosocial stress. Endocrinology 155:117-126

Gauthier JM, Lin A, Nic Dhonnchadha BA, Spealman RD, Man HY, Kantak KM (2017) Environmental enrichment facilitates cocainecue extinction, deters reacquisition of cocaine self-administration and alters AMPAR GluA1 expression and phosphorylation. Addict Biol 22:152-162

Grant BF, Stinson FS, Dawson DA, Chou SP, Dufour MC, Compton W, Pickering RP, Kaplan K (2004) Prevalence and co-occurrence of substance use disorders and independent mood and anxiety disorders: results from the National Epidemiologic Survey on alcohol and related conditions. Arch Gen Psychiatry 61:807-816

Grimm JW, Osincup D, Wells B, Manaois M, Fyall A, Buse C, Harkness JH (2008) Environmental enrichment attenuates cue-induced reinstatement of sucrose seeking in rats. Behav Pharmacol 19:777-785

Grinan-Ferre C, Izquierdo V, Otero E, Puigoriol-Illamola D, Corpas R, Sanfeliu C, Ortuno-Sahagun D, Pallas M (2018) Environmental enrichment improves cognitive deficits, $\mathrm{AD}$ hallmarks and epigenetic alterations presented in 5xFAD mouse model. Front Cell Neurosci $12: 224$

Hasin DS, Stinson FS, Ogburn E, Grant BF (2007) Prevalence, correlates, disability, and comorbidity of DSM-IV alcohol abuse and dependence in the United States: results from the National Epidemiologic Survey on alcohol and related conditions. Arch Gen Psychiatry 64:830-842

Heilig M, Goldman D, Berrettini W, O’Brien CP (2011) Pharmacogenetic approaches to the treatment of alcohol addiction. Nat Rev Neurosci 12:670-684

Heinrichs SC, Pich EM, Miczek KA, Britton KT, Koob GF (1992) Corticotropin-releasing factor antagonist reduces emotionality in socially defeated rats via direct neurotropic action. Brain Res 581:190197

Hess SE, Rohr S, Dufour BD, Gaskill BN, Pajor EA, Garner JP (2008) Home improvement: C57BL/6J mice given more naturalistic nesting materials build better nests. J Am Assoc Lab Anim Sci 47: 25-31

Huang H, Zhang X, Fu X, Zhang X, Lang B, Xiang X, Hao W (2018) Alcohol-induced conditioned place preference negatively correlates with anxiety-like behavior in adolescent mice: inhibition by a neurokinin-1 receptor antagonist. Psychopharmacology 235:28472857

Hwa LS, Holly EN, DeBold JF, Miczek KA (2016) Social stressescalated intermittent alcohol drinking: modulation by CRF-R1 in the ventral tegmental area and accumbal dopamine in mice. Psychopharmacology 233:681-690
Imperio CG, McFalls AJ, Hadad N, Blanco-Berdugo L, Masser DR, Colechio EM, Coffey AA, Bixler GV, Stanford DR, Vrana KE, Grigson PS, Freeman WM (2018) Exposure to environmental enrichment attenuates addiction-like behavior and alters molecular effects of heroin self-administration in rats. Neuropharmacology 139: 26-40

Li X, Meng L, Huang K, Wang H, Li D (2015) Environmental enrichment blocks reinstatement of ethanol-induced conditioned place preference in mice. Neurosci Lett 599:92-96

Lima FB, Spinelli de Oliveira E (2014) What is the impact of low testosterone levels on the anatomical and behavioral repertoire of longterm enriched housing of male mice? Behav Process 108:57-64

Lopatina O, Yoshihara T, Nishimura T, Zhong J, Akther S, Fakhrul AA, Liang M, Higashida C, Sumi K, Furuhara K, Inahata Y, Huang JJ, Koizumi K, Yokoyama S, Tsuji T, Petugina Y, Sumarokov A, Salmina AB, Hashida K, Kitao Y, Hori O, Asano M, Kitamura Y, Kozaka T, Shiba K, Zhong F, Xie MJ, Sato M, Ishihara K, Higashida $\mathrm{H}$ (2014) Anxiety- and depression-like behavior in mice lacking the CD157/BST1 gene, a risk factor for Parkinson's disease. Front Behav Neurosci 8:133

Lopez MF, Laber K (2015) Impact of social isolation and enriched environment during adolescence on voluntary ethanol intake and anxiety in C57BL/6J mice. Physiol Behav 148:151-156

Marcus DJ, Henderson-Redmond AN, Gonek M, Zee ML, Farnsworth JC, Amin RA, Andrews MJ, Davis BJ, Mackie K, Morgan DJ (2017) Mice expressing a "hyper-sensitive" form of the CB1 cannabinoid receptor (CB1) show modestly enhanced alcohol preference and consumption. PLoS One 12:e174826

McBlane JW, Handley SL (1994) Effects of two stressors on behaviour in the elevated X-maze: preliminary investigation of their interaction with 8-OH-DPAT. Psychopharmacology 116:173-182

McCormick CM, Smith C, Mathews IZ (2008) Effects of chronic social stress in adolescence on anxiety and neuroendocrine response to mild stress in male and female rats. Behav Brain Res 187:228-238

Nephew BC, Bridges RS (2011) Effects of chronic social stress during lactation on maternal behavior and growth in rats. Stress 14:677684

Newman EL, Albrechet-Souza L, Andrew PM, Auld JG, Burk KC, Hwa LS, Zhang EY, DeBold JF, Miczek KA (2018) Persistent escalation of alcohol consumption by mice exposed to brief episodes of social defeat stress: suppression by CRF-R1 antagonism. Psychopharmacology 235:1807-1820

Nithianantharajah J, Hannan AJ (2006) Enriched environments, experience-dependent plasticity and disorders of the nervous system. Nat Rev Neurosci 7:697-709

Norman KJ, Seiden JA, Klickstein JA, Han X, Hwa LS, DeBold JF, Miczek KA (2015) Social stress and escalated drug selfadministration in mice I. Alcohol and corticosterone Psychopharmacology (Berl) 232:991-1001

Nyuyki KD, Beiderbeck DI, Lukas M, Neumann ID, Reber SO (2012) Chronic subordinate colony housing (CSC) as a model of chronic psychosocial stress in male rats. PLoS One 7:e52371

Okhuarobo A, Igbe I, Yahaya A, Sule Z (2018) Effect of caffeine on alcohol consumption and alcohol-induced conditioned place preference in rodents. J Basic Clin Physiol Pharmacol 30:19-28

Pang TY, Hannan AJ, Lawrence AJ (2019) Novel approaches to alcohol rehabilitation: modification of stress-responsive brain regions through environmental enrichment. Neuropharmacology 145:25-36

Pellow S, Chopin P, File SE, Briley M (1985) Validation of open:closed arm entries in an elevated plus-maze as a measure of anxiety in the rat. J Neurosci Methods 14:149-167

Pham TM, Ickes B, Albeck D, Soderstrom S, Granholm AC, Mohammed AH (1999) Changes in brain nerve growth factor levels and nerve growth factor receptors in rats exposed to environmental enrichment for one year. Neuroscience 94:279-286 
Reber SO, Birkeneder L, Veenema AH, Obermeier F, Falk W, Straub RH, Neumann ID (2007) Adrenal insufficiency and colonic inflammation after a novel chronic psycho-social stress paradigm in mice: implications and mechanisms. Endocrinology 148:670-682

Reber SO, Obermeier F, Straub RH, Veenema AH, Neumann ID (2008) Aggravation of DSS-induced colitis after chronic subordinate colony (CSC) housing is partially mediated by adrenal mechanisms. Stress 11:225-234

Rodgers RJ, Cole JC (1993) Anxiety enhancement in the murine elevated plus maze by immediate prior exposure to social stressors. Physiol Behav 53:383-388

Rodriguez-Arias M, Navarrete F, Blanco-Gandia MC, Arenas MC, Bartoll-Andres A, Aguilar MA, Rubio G, Minarro J, Manzanares J (2016) Social defeat in adolescent mice increases vulnerability to alcohol consumption. Addict Biol 21:87-97

Rosenzweig MR, Bennett EL (1996) Psychobiology of plasticity: effects of training and experience on brain and behavior. Behav Brain Res 78:57-65

Rygula R, Abumaria N, Havemann-Reinecke U, Ruther E, Hiemke C, Zernig G, Fuchs E, Flugge G (2008) Pharmacological validation of a chronic social stress model of depression in rats: effects of reboxetine, haloperidol and diazepam. Behav Pharmacol 19:183196

Sale A (2018) A systematic look at environmental modulation and its impact in Brain development. Trends Neurosci 41:4-17

Sanberg PR (1989) Neuroleptic-induced emotional defecation: effects of pimozide and apomorphine. Physiol Behav 46:199-202

Schnabel J (2009) Neuroscience: rethinking rehab. Nature 458:25-27

Sedki F, Abbas Z, Angelis S, Martin J, D'Cunha T, Shalev U (2013a) Is it stress? The role of stress related systems in chronic food restrictioninduced augmentation of heroin seeking in the rat. Front Neurosci 7: 98

Sedki F, D'Cunha T, Shalev U (2013b) A procedure to study the effect of prolonged food restriction on heroin seeking in abstinent rats. J Vis Exp:e50751

Segovia G, Del Arco A, de Blas M, Garrido P, Mora F (2008) Effects of an enriched environment on the release of dopamine in the prefrontal cortex produced by stress and on working memory during aging in the awake rat. Behav Brain Res 187:304-311

Singewald GM, Nguyen NK, Neumann ID, Singewald N, Reber SO (2009) Effect of chronic psychosocial stress-induced by subordinate colony (CSC) housing on brain neuronal activity patterns in mice. Stress 12:58-69

Slattery DA, Uschold N, Magoni M, Bar J, Popoli M, Neumann ID, Reber SO (2012) Behavioural consequences of two chronic psychosocial stress paradigms: anxiety without depression. Psychoneuroendocrinology 37:702-714

Smith MA, Chisholm KA, Bryant PA, Greene JL, McClean JM, Stoops WW, Yancey DL (2005) Social and environmental influences on opioid sensitivity in rats: importance of an opioid's relative efficacy at the mu-receptor. Psychopharmacology 181:27-37

Solinas M, Chauvet C, Thiriet N, El Rawas R, Jaber M (2008) Reversal of cocaine addiction by environmental enrichment. Proc Natl Acad Sci U S A 105:17145-17150
Solinas M, Thiriet N, El Rawas R, Lardeux V, Jaber M (2009) Environmental enrichment during early stages of life reduces the behavioral, neurochemical, and molecular effects of cocaine. Neuropsychopharmacology 34:1102-1111

Stefanski V (2001) Social stress in laboratory rats: behavior, immune function, and tumor metastasis. Physiol Behav 73:385-391

Tamashiro KL, Nguyen MM, Fujikawa T, Xu T, Yun Ma L, Woods SC, Sakai RR (2004) Metabolic and endocrine consequences of social stress in a visible burrow system. Physiol Behav 80:683-693

Tamashiro KL, Hegeman MA, Nguyen MM, Melhorn SJ, Ma LY, Woods SC, Sakai RR (2007) Dynamic body weight and body composition changes in response to subordination stress. Physiol Behav 91:440448

Thiel KJ, Painter MR, Pentkowski NS, Mitroi D, Crawford CA, Neisewander JL (2012) Environmental enrichment counters cocaine abstinence-induced stress and brain reactivity to cocaine cues but fails to prevent the incubation effect. Addict Biol 17:365-377

Thiriet N, Gennequin B, Lardeux V, Chauvet C, Decressac M, Janet T, Jaber M, Solinas M (2011) Environmental enrichment does not reduce the rewarding and neurotoxic effects of methamphetamine. Neurotox Res 19:172-182

Vahid-Ansari F, Daigle M, Manzini MC, Tanaka KF, Hen R, Geddes SD, Beique JC, James J, Merali Z, Albert PR (2017) Abrogated Freud-1/ Cc2d1a repression of 5-HT1A autoreceptors induces fluoxetineresistant anxiety/depression-like behavior. J Neurosci 37:1196711978

van Praag H, Kempermann G, Gage FH (2000) Neural consequences of environmental enrichment. Nat Rev Neurosci 1:191-198

Veena J, Srikumar BN, Mahati K, Bhagya V, Raju TR, Shankaranarayana Rao BS (2009) Enriched environment restores hippocampal cell proliferation and ameliorates cognitive deficits in chronically stressed rats. J Neurosci Res 87:831-843

Veenema AH, Reber SO, Selch S, Obermeier F, Neumann ID (2008) Early life stress enhances the vulnerability to chronic psychosocial stress and experimental colitis in adult mice. Endocrinology 149: 2727-2736

Xie Q, Buck LA, Bryant KG, Barker JM (2019) Sex differences in ethanol reward seeking under conflict in mice. Alcohol Clin Exp Res 43:1556-1566

Zheng D, Cabeza de Vaca S, Carr KD (2012) Food restriction increases acquisition, persistence and drug prime-induced expression of a cocaine-conditioned place preference in rats. Pharmacol Biochem Behav 100:538-544

Zuo W, Fu R, Hopf FW, Xie G, Krnjevic K, Li J, Ye JH (2017) Ethanol drives aversive conditioning through dopamine 1 receptor and glutamate receptor-mediated activation of lateral habenula neurons. Addict Biol 22:103-116

Publisher's note Springer Nature remains neutral with regard to jurisdictional claims in published maps and institutional affiliations. 